\title{
Examination of marital adjustment and sexuality in patients with schizophrenia
}

\author{
Shabnam Fatalizade $\odot$, Salih Saygın Eker $\odot$ \\ Department of Psychiatry, Bursa Uludă̆ University School of Medicine, Bursa, Turkey
}

\begin{abstract}
Objectives: The main aim of the study is to compare marital adjustment and sexuality in schizophrenia patients. Methods: The sample of the study consists of 48 outpatients with a diagnosis of schizophrenia according to DSM V by the Department of Psychiatry, Bursa Uludağ University School of Medicine and 48 healthy volunteers. Sociodemographic Information Form, Marriage Adjustment Scale (MAS), Arizona Sexual Experiences Scale (ASEX) - (Female and Male form) are applied to both groups.

Results: A significant difference was observed between individuals with schizophrenia and healthy group according to sexual dysfunction. The incidence of sexual dysfunction in schizophrenia patients is high. While the average values of the individuals' MAS were higher in the healthy group, no significant difference was found between the groups according to the MAS total score.

Conclusions: There is no difference in terms of compliance with marriage between the healthy group and schizophrenic patients, but there is a difference in terms of sexual function. Data from this study suggest that schizophrenia may not be a factor in marital adjustment but may be a factor that may cause sexual dysfunction. All schizophrenic patients in our study used drugs. It cannot be ruled out that drug use may cause sexual dysfunction.
\end{abstract}

Keywords: Schizophrenia, marital satisfaction, marital adjustment, sexual satisfaction

S chizophrenia is a mental disorder that begins at a young age, causing the individual to keep himself away from human relations and realities, to be attracted to his inner world, paving the way for significant disturbances in emotions, thoughts and behaviors, bringing along loss of work power [1]. It is a chronic disorder that is seen in both sexes, even though it is usually seen less in women than men, it follows a worse course in men. The age of onset is often in young adulthood, but it can also begin later, especially as in the case of women [1-3]. The progression and termination of the disease vary depending on the patients. This disease is a public health problem in which symptoms and signs can be seen in all areas of mental state [4]. Although schizophrenia is known to be multifactorial; genetic predisposition, environmental factors, and perinatal factors are thought to play a role frequently in its etiology [5]. Today, in its treatment, medical treatment and Electroconvulsive Therapy (EKT), being in the first place, and psychoynamic approaches such as, Cognitive Behavioral Therapy (CBT) and group therapy can be used as supportive therapy [6]. According to the general population, the rate of marriage is lower and divorce rates are higher in schizophrenia patients [7]. Despite the lack of evidence that marriages play a protective role, Eatol's study of ş schizophrenia and marriage en in 1975 found that morbidity was higher in never-married 
schizophrenic patients than in divorced patients [8]. relationship [9]. Studies have reported that schizophreAlthough the disease affects many aspects of sexuality, nia patients have an interest in sexuality but have difa number of patients can develop a meaningful close ficulty in expressing it [10].

Table 1. Comparison of schizophrenic and healthy group in terms of sociodemographic data

\begin{tabular}{|c|c|c|c|}
\hline & $\begin{array}{l}\text { Schizophrenia } \\
\quad(\mathrm{n}=48)\end{array}$ & $\begin{array}{l}\text { Healthy } \\
(n=48)\end{array}$ & $p$ value \\
\hline Age (years) & $52.50(21-65)$ & $49(30-67)$ & 0.207 \\
\hline \multicolumn{4}{|l|}{ Gender (F/M) } \\
\hline Female & $20(41.70 \%)$ & $17(35.40 \%)$ & 0.529 \\
\hline Male & $28(58.3 \%)$ & $31(64.60 \%)$ & \\
\hline \multicolumn{4}{|l|}{ Employment status } \\
\hline Working & $12(25 \%)$ & $38(79.20 \%)$ & $<0.001$ \\
\hline Not working & $36(75 \%)$ & $10(20.80 \%)$ & \\
\hline \multicolumn{4}{|l|}{ Educational attainment } \\
\hline Less than high school & $33(68.80 \%)$ & $10(20.80 \%)$ & $<0.001$ \\
\hline High school & $10(20.80 \%)$ & $26(54.20 \%)$ & \\
\hline Undergraduate and graduate & $5(10.40 \%)$ & $12(25 \%)$ & \\
\hline \multicolumn{4}{|l|}{ Profession } \\
\hline State servant & $8(16.70 \%)$ & $22(45.80 \%)$ & 0.004 \\
\hline Worker & $20(41.70 \%)$ & $18(37.50 \%)$ & \\
\hline Unemploved & $9(18.80 \%)$ & $6(12.50 \%)$ & \\
\hline Retired & $11(22.90 \%)$ & $2(4.20 \%)$ & \\
\hline Income (TL)) & & & $<0.001$ \\
\hline $0-1,500$ & $23(47.90 \%)$ & $8(16.70 \%)$ & \\
\hline $1,501-3,000$ & $23(47.90 \%)$ & $23(47.90 \%)$ & \\
\hline $3,001-4,500$ & $1(2.10 \%)$ & $9(18.80 \%)$ & \\
\hline$>4,500$ & $1(2.10 \%)$ & $8(16.70 \%)$ & \\
\hline Lenght of marriage (year) & $3(1-3)$ & $3(1-3)$ & 0.390 \\
\hline \multicolumn{4}{|l|}{ Cohabiting relatives } \\
\hline Wife/husband & $23(47.90 \%)$ & $28(58.30 \%)$ & 0.306 \\
\hline $\begin{array}{l}\text { Wife/husband \& other } \\
\text { relatives \& children }\end{array}$ & $25(52.10 \%)$ & $20(41.70 \%)$ & \\
\hline \multicolumn{4}{|l|}{ Sexual dysfunction } \\
\hline No & $6(12.50 \%)$ & $33(68.80 \%)$ & $<0.001$ \\
\hline Yes & $42(87.50 \%)$ & $15(31.30 \%)$ & \\
\hline \multicolumn{4}{|l|}{ Marriage adjustment } \\
\hline Compatible & $28(58.30 \%)$ & $35(72.90 \%)$ & 0.133 \\
\hline Incompatible & $20(41.70 \%)$ & $13(27.10 \%)$ & \\
\hline MC total & $41.92 \pm 12.57$ & $47.25 \pm 7.88$ & 0.015 \\
\hline ASEX total & $20(5-29)$ & $10(5-28)$ & $<0.001$ \\
\hline
\end{tabular}

Data are expressed as mean \pm standard deviation, median (minimum- maximum) and $\mathrm{n}(\%)$. 


\section{METHODS}

The sample of the study consists of 48 outpatients with a diagnosis of schizophrenia according to DSM V by the Department of Psychiatry, Bursa Uludag University School of Medicine and 48 healthy volunteers. Sociodemographic Information Form, Marriage Adjustment Scale (MAS), Arizona Sexual Experiences Scale (ASEX) - (Female and Male form) are are given to patients and healthy group.

Participants are between the ages of 18-65 and married, they are not mentally retarded and do not have physical disorders that cause sexual dysfunction. Those with any systemic disease (diabetes, coronary heart disease, prostate) that could prevent their sexuality were excluded from the study. The aim of the study is to see whether the disease affects sexual function. All schizophrenic patients included in the study are drug users.

\section{Arizona Sexual Experiences Scale (ASEX)}

It consists of five items of six Likert type, consisting of male and female forms. 11 and above points indicate sexual dysfunction [11].

\section{Marital Adjustment Test (MAT)}

Scoring in the scale increases from noncompliance to compliance. The lowest compliance score is found to be 2 , the highest compliance score is 58 , and the cut-off point is 43,5 . The lower total score in the scale points out mismatch in the marriage, the higher total score in the scale points out adjustment in the marriage [12].

\section{Statistical Analysis}

The conformity of the variables to the normal distribution is investigated by ShapiroWilk test. Continuous variables are expressed with median (minimum: maximum) and mean \pm standard deviation values. Categorical variables are expressed in $n(\%)$. According to the results of normality test, Mann Whitney $U$ and independent double sample t tests were used in the comparisons between the two groups. Pearson Chi - Square, Fisher's exact Chi - Square and Fisher - Freeman - Halton tests were used for the comparison of categorical variables. For statistical analysis, SPSS (IBM Corp. Released 2012. IBM SPSS Statisticsfor Windows, Version21.0. Armonk, NY:
IBM Corp.) was used and $p<0.05$ is considered statistically significant.

\section{RESULTS}

Table 1 shows the demographic characteristics of schizophrenic and healthy group. Table 2 presents questions that are unique to schizophrenia patients and patient characteristics. In Table 3, there is no difference between the groups in the schizophrenia group according to the marriage compliance scale. As a result of the classification made within the

Table 2. Disease characteristics of schizophrenia group $(n=48)$

\begin{tabular}{|cc}
\hline $\begin{array}{l}\text { Did the disease start during } \\
\text { marriage? }\end{array}$ & Data \\
\hline Yes & $34(70.80 \%)$ \\
\hline No & $14(29.20 \%)$ \\
\hline $\begin{array}{c}\text { Duration of treatment (years) } \\
0-5 \text { years }\end{array}$ & $12(25 \%)$ \\
$6-10$ years & $10(20.80 \%)$ \\
\hline$>10$ years & $26(54.20)$ \\
\hline Hospitalization & \\
\hline Yes & $32(66.70 \%)$ \\
\hline No & $16(33.30 \%)$ \\
\hline Number of hospitalizations & $27(84.40 \%)$ \\
\hline $0-5$ & $2(6.30 \%)$ \\
\hline $6-10$ & $3(9.40 \%)$ \\
\hline 10 & \\
\hline Did he have an attack & $37(77.10 \%)$ \\
\hline Yes & $11(22.90 \%)$ \\
\hline No & $25(52.10 \%)$ \\
\hline Number of attacks & $3(6.30 \%)$ \\
\hline $0-5$ & $9(41.60 \%)$ \\
\hline $6-10$ & $14(29.20 \%)$ \\
\hline$>10$ & $9(18.80 \%)$ \\
\hline $0-5$ & $25(52.10 \%)$ \\
\hline $6-10$ & \\
\hline$>10$ & \\
\hline
\end{tabular}

The data are expressed as $\mathrm{n}(\%)$. 
Table 3. Evaluation of marital adjustment in schizophrenia group

\begin{tabular}{|cccc}
\hline & \multicolumn{2}{c}{ Marriage Compliance: } & p value \\
\cline { 2 - 3 } & $\begin{array}{c}\text { Compatible } \\
(\mathbf{n}=\mathbf{2 8})\end{array}$ & $\begin{array}{c}\text { Incompatible } \\
(\mathbf{n}=\mathbf{2 0})\end{array}$ & \\
\hline $\begin{array}{cccc}\text { Lenght of marriage } \\
\text { Drug Use (years) }\end{array}$ & $3(1-3)$ & $3(1-3)$ & 0.658 \\
\hline $0-5$ & $10(35.70 \%)$ & $4(20 \%)$ & 0.489 \\
\hline $6-10$ & $5(17.90 \%)$ & $4(20 \%)$ & \\
\hline 10 & $13(46.40 \%)$ & $12(60 \%)$ & 0.679 \\
\hline Hospitalization & $18(64.30 \%)$ & $14(70 \%)$ & 0.809 \\
\hline Yes & $10(35.70 \%)$ & $6(30 \%)$ & 0.499 \\
\hline No & $1(1-2)$ & $1(1-2)$ & \\
\hline Number of children & & & \\
\hline Working & $8(28.60 \%)$ & $4(20 \%)$ & 0.218 \\
\hline Not working & $20(71.40 \%)$ & $16(80 \%)$ & \\
\hline No & $2(7.10 \%)$ & $4(20 \%)$ & $16(80 \%)$ \\
\hline Yes & $26(92.90 \%)$ & & \\
\hline
\end{tabular}

Data are expressed as median (minimum- maximum), $\mathrm{n}(\%)$.

schizophrenia group; there is no difference between the groups with and without sexual dysfunction according to the variables in table 4. In tables:
Duration of marriage was 3 (1-3) 0-5, 6-10, $11>$; number of children $1(1-2) 0-5$ and $6>$.

Table 4. Evaluation of sexual dysfunction in schizophrenia group

\begin{tabular}{|c|c|c|c|}
\hline & \multicolumn{2}{|c|}{ Sexual dysfunction } & \multirow[t]{2}{*}{$p$ value } \\
\hline & $\begin{array}{c}\text { No } \\
(n=6)\end{array}$ & $\begin{array}{c}\text { Yes } \\
(n=42)\end{array}$ & \\
\hline Lenght of marriage & $3(3-3)$ & $3(1-3)$ & 0.367 \\
\hline \multicolumn{4}{|l|}{ Drug Use (years) } \\
\hline $0-5$ & $2(33.30 \%)$ & $12(28.60 \%)$ & 1.00 \\
\hline $6-10$ & $1(16.70 \%)$ & $8(19 \%)$ & \\
\hline$>10$ & $3(50 \%)$ & $22(52.40 \%)$ & \\
\hline Number of children & $1(1-1)$ & $1(1-2)$ & 0.867 \\
\hline \multicolumn{4}{|l|}{ Employment status } \\
\hline Working & 0 & $12(28.60 \%)$ & 0.315 \\
\hline Not working & $6(100 \%)$ & $30(71.40 \%)$ & \\
\hline
\end{tabular}

Data are expressed as median (minimum: maximum), $\mathrm{n}(\%)$. 


\section{DISCUSSION}

The data we have obtained in this section will be reviewed in the light of the general literature. In our study, sociodemographic data obtained from schizophrenia patients were consistent with the data in the general literature $[1,3]$. The fact that only $25 \%$ of patients in the study group are working, can be associated with low levels of general education and demolition caused by disease [13]. Parallel to this, income levels are also low compared to the general population [14]. As a result of disease and socioeconomic conditions, patients with schizophrenia need social support while continuing their lives [13, 14]. In our study (Table 2), disease characteristics such as hospitalization and number of attacks were also consistent with the general literature [15]. In our study, no difference was found between sexes according to treatment periods. Similarly, in the literature, it is thought that a number of possible differences have disappeared over time as patients have a very long disease process [16].

In the literature, there are very few studies on the sexual dysfunctions of schizophrenia patients. Our findings were also consistent with the literature [1719]. The study conducted in Turkey by Hocaoglu et al. [17] with a group of 101 patients with schizophrenia and 89 healthy persons using ASEX scale, showed that $46 \%$ of male patients with schizophrenia and $68 \%$ of female patients with schizophrenia has sexual function disorder. Ghadirian et al. [19] found in their study with 55 patients with schizophrenia using antipsychotic drugs that $54 \%$ of males and $30 \%$ of females had sexual dysfunction. In a study of 7655 patients with schizophrenia, Dossenbach et al. [18] reported that a form of sexual dysfunction was present in approximately half of the patients. In a study performed by Uçok et al. [20], 826 patients with schizophrenia were found to have sexual dysfunction disorder in $52.6 \%$ of patients according to ASEX scale.

When the data of our study were examined, even though there is no statistically significant difference between the schizophrenia group and the control group in terms of marital adjustment, the total marital adjustment scores of the schizophrenic patients are lower than those of the healthy group. In our literature review, there was no study about marital adjustment and satisfaction among patients with schizophrenia. As a result of the classification of patients according to MAS, no difference is found between the groups with and without marital adjustment (according to the variables in Table 3 ). These variables may not have determined the harmony of marriage. Patients are thought to be more indicative of the more abstract understanding of marriage.

As shown in Table 4 within the schizophrenia group, it was found that the variables such as duration of marriage, duration of drug use, number of children and working status did not have any effect on sexual function.

\section{CONCLUSION}

There is no difference in terms of marriage adjustment, between the groups of healthy individuals and schizophrenic patients, but there was a difference in terms of sexual function. Data from this study suggest that schizophrenia may not be a factor in marital adjustment but may be a factor that may cause sexual dysfunction. All schizophrenic patients in our study used drugs. It cannot be ruled out that drug use may cause sexual dysfunction. However, there is no difference observed between the schizophrenia patients who have sexual dysfunction or not, due to the duration of drug use. The studies which will be performed with bigger numbers of patients will provide a more healthy evaluation of the data we have obtained.

\section{Authorship declaration}

All authors listed meet the authorship criteria according to the latest guidelines of the Internaional Committe of Medical Journal Editors, and all authors are in agreement with the manuscript.

\section{Conflict of interest}

The authors disclosed no conflict of interest during the preparation or publication of this manuscript.

\section{Financing}

The authors disclosed that they did not receive any grant during conduction or writing of this study. 


\section{REFERENCES}

1. Öztürk O, Uluşahin A. Mental health and disorders. 14th ed., Nobel Medicine Book Houses Ltd.: Ankara, 2016: pp.189-244.

2. Rock Dolphin. Social functionality of schizophrenic patients and caregivers of patients. Hacettepe University Institute of Health Sciences. Master Thesis. 2013.

3. Black DW, Andreasen NC. Introductory Textbook of Psychiatry. Washington, DC: American Psychiatric Publishing Inc., 2011.

4. Kocal Y, Karakuş G, Ok L. [Sociodemographic and clinical characteristics of inpatients with schizophrenia in psychiatry clinics]. Klinik Psikiyatri 2017;20;104-13. [Article in Turkish] 5. Ceylan, ME, Cetin M. Biology Psychiatry in Research and Clinical Practice, 3th ed., Istanbul: Earth Promotion and Publishing Services Inc. 2005.

6. Dinçer N. Evaluation of the Relationship Between Personality Traits and Carer Loads of Persons Caring for Patients with Diagnosis of Psychosis. Unpublished master's thesis, Uludag University Institute of Health Sciences. 2017.

7. Köroğlu E. Psychonozology, Descriptive Clinical Psychiatry, Ankara: Physicians Publication Association, 2004:210.

8. Abernethy V. Sexual knowledge, attitudes, and practices of young female psychiatric patients. Arch Gen Psychiatry 1974;30:180-2.

9. Volman L, Landeen J. Uncovering the sexual self in people with schizophrenia. J Psychiatr Ment Health Nurs 2007;14:4117.

10. Işık H, Aker T. Sexual life of patients with schizophrenia. 36th National Psychiatry Congress, Antalya. 2000.

11. Özdemir L, Kalyoncu U, Akdemir N. [The evaluation of sexual problems and influencing factors in Behçet's disease]. Trakya Univ Tip Fak Derg 2010;27:238-42. [Article in Turkish] 12. Temeloğlu Şen E, Uzun Oğuz E. [Person's who have psychiatric diagnosis and his spouse's marital adjustment]. HSP 2017;4:16-24. [Article in Turkish]

13. Belli H, Özçetin A, Ertem Ü, Alpay E, Bahçebaşı T, Kıran ÜK, et al. [Some sociodemographic characteristics and treatmentrelated factors in schizophrenia patients]. Anadolu Psikiyatri Derg 2007;8:102-111. [Article in Turkish]

14. Atmaca GD. Relationship of suicide probability with depression and insight in patients with schizophrenia. Master's thesis. 2016.

15. Salokangas RK. Prognostic implications of schizophrenic patients. Br J Psychiatry 1983;142:145-51.

16. Seeman MV. Psychopathology in women and men: focus on female hormones. Am J Psychiatry 1997;154:1641-7.

17. Hocaoglu C, Celik FH, Kandemir G, Guveli H, Bahceci B. Sexual dysfunction in outpatients with schizophrenia in Turkey: a cross-sectional study. Shanghai Arch Psychiatry 2014;26:34756.

18. Dossenbach M, Hodge A, Anders M, Molnar B, Peciukaitiene D, Krupka-Matuszczyk I, et al. Prevalence of sexual dysfunction in patients with schizophrenia: international variation and underestimation. Int J Neuropsychopharmacol 2005;8:195-201. 19. Ghadirian AM, Chouinard G, Annable L. Neuroleptic-treated schizophrenic outpatients. J Nerv Ment Dis 1982;170:463-7.

20. Uçok A, Incesu C, Aker T, Erkoç Ş. Sexual dysfunction in patients with schizophrenia on antipyschotic medication. Eur Psychiatry 2007;22:328-33. 